\title{
Attitudes towards alcohol and alcohol-related problems: Comparison among nurses from different Brazilian health care settings
}

\author{
Marina Nolli Bittencourt * Divane de Vargas \\ School of Nursing, Sao Paulo University, Sao Paulo, Brazil
}

Received: August 18, 2014

DOI: $10.5430 /$ jnep.v5n2p45

Accepted: November 10, 2014 Online Published: November 20, 2014

URL: http://dx.doi.org/10.5430/jnep.v5n2p45

\begin{abstract}
Objective: This descriptive, exploratory study sought to compare the attitudes of nurses from different health care settings towards alcohol, alcoholism and alcoholics.

Method: A total of 526 nurses working at several Brazilian health care facilities participated in this study by answering a 96item attitude scale. The Kruskal-Wallis test was used to compare the attitudes of the participants according to their health care setting, and a multiple comparisons test was used to identify the groups in which this difference was statistically significant.

Results: The results showed that nurses working at specialized facilities displayed more positive attitudes towards alcoholics (working and interpersonal relations) and alcohol but negative attitudes towards alcoholism and its etiology when compared to the other nurses.

Conclusion: This study suggests that nurses' attitudes towards alcohol and alcohol-related problems differ depending on the health care setting; in particular, nurses working at specialized facilities tend to show more positive attitudes than nurses working in other health care facilities toward alcohol-related problems.
\end{abstract}

Key Words: Attitude, Alcoholism, Nurses, Health services

\section{Introduction}

Data indicate that between 2008 and 2010, the global amount of alcohol consumed per capita was 6.2 liters. ${ }^{[1]}$ In particular, Europe showed the highest per capita alcohol consumption at 10.9 liters followed by the Americas at 8.4 liters. ${ }^{[1]}$ In Brazil between 2008 and 2010, the per capita alcohol consumption was 8.7 liters, ${ }^{[1]}$ and national estimates also indicate that $74.6 \%$ of the population uses or has used alcohol. ${ }^{[2]}$ Evidence of the consequences of alcohol abuse are well documented in the literature and currently represent a phenomenon that has contributed to several social and health impairments in populations from all regions of the world. ${ }^{[1]}$

The magnitude of this problem on public health is evidenced by the high prevalence of individuals with problems associated with alcohol use at health care facilities, such as hospital inpatient units, emergency rooms and extra-hospital facilities. ${ }^{[3-5]}$ Despite nurses being the professionals with extensive contact with the users of alcohol or other substances in these health care facilities, Crothers and Dorrian $^{[6]}$ demonstrated that these professionals do not have proper training to address the problem, which results in a re-

*Correspondence: Marina Nolli Bittencourt; Email: marinanolli@usp.br; Address: School of Nursing, Sao Paulo University, Sao Paulo, Brazil. 
duced ability to work with these patients and, consequently, negative attitudes toward individuals with alcohol-related problems. Therefore, Nehlin and colleagues ${ }^{[7]}$ found that nurses' attitudes toward patients with alcohol-related problems are important, regardless of where they work, to ensure successful strategies to detect and address this problem. In particular, nurses have been identified as important agents to detect, refer and treat patients with alcohol-related problems. ${ }^{[8,9]}$

Warren and colleagues, ${ }^{[8]}$ and Kelleher and Cotter ${ }^{[10]}$ in recent studies indicated that nurses' attitudes towards alcohol, alcoholism and alcoholics have been more positive compared to the attitudes assessed in studies ${ }^{[11,12]}$ conducted in the 80s and 90s. In addition, Nehlin and colleagues, ${ }^{[7]}$ Crothers and Dorrian, ${ }^{[6]}$ and Vargas ${ }^{[13]}$ revealed that education and training, personal characteristics and the pattern of alcohol consumption itself are common variables that influence nurses' attitudes towards alcohol and alcoholics. The attitudes of nurses from several health care facilities towards alcohol and alcohol-related problems have been well documented in both the Brazilian and international literature in the past decade. ${ }^{[6,8,14]}$ However, although evidence has shown that the workplace influences the attitudes of these professionals toward patients with alcohol-related problems, ${ }^{[15,16]}$ studies comparing possible differences in attitudes of nurses working at different health care service sites are limited.

According to studies of Luis and Lunetta, ${ }^{[17]}$ and Willaing and Ladelund, ${ }^{[16]}$ nurses working at specialized alcohol/other drug treatment facilities tend to show more positive attitudes towards alcoholics, exhibiting less moralistic attitudes. In addition, although nurses from specialized health care units were shown to display a more positive attitude towards alcoholics, Willaing and Ladelund ${ }^{[16]}$ found that nurses from general health care units expressed a more tolerant attitude toward alcohol use. Thus, considering that studies aiming to compare nurses' attitudes are incipient and limited to few health care facilities and that understanding the differences in nurses' attitudes is important for developing concrete and specific strategies for drug and alcohol training at a variety of health care facilities, this study sought to compare the attitudes of nurses working at different health care settings towards alcohol, alcoholism and alcoholics.

\section{Methods}

This was a descriptive, exploratory study with the objective of comparing the attitudes of nurses working at different Brazilian health care settings towards alcohol, alcoholism and alcoholics. The study was conducted in 20 general hospitals, 20 specialized alcohol/other drug treatment facilities, 50 primary health care facilities and 18 mental health facilities located in São Paulo city, state of São Paulo, Brazil. The sample consisted of 526 nurses divided into the following 4 groups: Group 1) 298 nurses working at general hospitals; Group 2) 153 nurses working at primary health care facilities; Group 3) 31 nurses working at mental health facilities; Group 4) 44 nurses working at specialized alcohol and other drug treatment facilities.

The Scale of Attitudes towards Alcohol, Alcoholism and Alcoholics (Escala de Atitudes frente ao Álcool, ao Alcoolismo, e ao Alcoolista - EAFAAA) was used to assess nurses' attitudes. According Vargas, ${ }^{[13]}$ the reliability test of the 96-item EAFAAA version resulted in a Cronbach's $\alpha$ of 0.9068. Regarding the individual reliability of the factors, factor 1 presented the highest index (0.9178). The other factors also had satisfactory results close to the 0.90 , except for factor 5 with an (a) coefficient of 0.4771 .

This instrument consists of 96 items that are answered using a 5-point Likert scale. The items are divided into 5 subscales: S1) attitudes towards alcoholics (work and interpersonal relations) - 42 items (average score $=126$ ); S2) attitudes towards the etiology of alcoholism - 20 items (average score $=60$ ); S3) attitudes towards alcoholism - 13 items (average score $=39$ ); S4) attitudes towards the repercussions deriving from alcohol use/abuse - 9 items (average score $=27$ ); and S5) attitudes towards alcoholic beverages 12 items (average score $=36$ ). Vargas $(2012)$ indicates that EAFAAA is predominantly negative, 72 EAFAAA items are oriented positively, which means that, the higher the disagreement of the subjects towards the item, the more positive their attitudes. Therefore, for the interpretation of data collected with this scale, the answers to the items was calculated with inverted values, with the scores computed as follows: $(1=5),(2=4),(3=3),(4=2),(5=1)$. Consequently, high scores (above-average scores) showed positive attitudes, while low scores (below average scores) tended to reflect negative attitudes.

Socio-demographic data were obtained using a questionnaire with 8 questions, divided into the following three sections: section 1) demographic characteristics of the subjects; section 2) professional practice; and section 3) nursing training. The data were collected from January to October 2010.

A database was created in the program Statistical Package for Social Science (SPSS ${ }^{\circledR}$ ) Version 18.0 for Windows ${ }^{\circledR}$ for data analysis. Regarding the socio-demographic data, the quantitative variable age was described as the mean and standard deviation $(S D)$, while absolute frequencies were calculated for categorical variables. Cronbach's $\alpha$ was used to measure the reliability of the questionnaire for this sample. To analyze the nurses' attitudes according to the health care setting, the scores initially obtained for each of the four groups of nurses in the full instrument and each of the subscales were identified. After these scores were identified, the scores were compared among the groups using the package Predictive Analytics Software (PASW ${ }^{\circledR}$ ) Ver- 
sion 18.0. Analysis of variance using the non-parametric Kruskal-Wallis test was performed for non-normally distributed data. To test for significant differences in nurses' attitudes according to the variable workplace, the StudentNewman-Keuls (SNK) multiple comparison test was used. A significance level of $5 \%$ was used for all tests.

Table 1: Distribution of the participants according to their socio-demographic data and workplace $(n=526)$. São Paulo, 2013

\begin{tabular}{|c|c|c|c|c|}
\hline \multirow[t]{2}{*}{ Socio-demographic Data } & \multirow{2}{*}{$\begin{array}{l}\text { General Hospital } \\
(\mathrm{n}=298)\end{array}$} & \multirow{2}{*}{$\begin{array}{l}\text { Primary Health } \\
\text { Care } \\
(\mathrm{n}=153)\end{array}$} & \multirow{2}{*}{$\begin{array}{l}\begin{array}{l}\text { Mental Health } \\
\text { Facilities } \\
(\mathbf{n}=31)\end{array} \\
\mathbf{N}(\%)\end{array}$} & \multirow{2}{*}{$\begin{array}{l}\begin{array}{l}\text { Specialized } \\
\text { Facilities } \\
(\mathbf{n}=44)\end{array} \\
\mathrm{N}(\%)\end{array}$} \\
\hline & & & & \\
\hline Age (mean+/-SD) & $34.93+/-9.71$ & $33.32+/-8.69$ & $35.26+/-10.31$ & $39.27+/-11.15$ \\
\hline \multicolumn{5}{|l|}{ Gender } \\
\hline Female & 261(87.6) & $129(84.3)$ & $22(71.0)$ & $35(79.5)$ \\
\hline Male & $37(12.4)$ & $24(15.7)$ & $9(29.0)$ & $9(20.5)$ \\
\hline Total & $258(100)$ & $153(100)$ & $31(100)$ & $44(100)$ \\
\hline \multicolumn{5}{|l|}{ Marital status } \\
\hline Married & 127(42.6) & $62(40.5)$ & $15(48.4)$ & $15(34.1)$ \\
\hline Single & 144(48.3) & $68(44.4)$ & $12(38.7)$ & $7(15.9)$ \\
\hline Divorced & $17(5.7)$ & $12(7.8)$ & $2(6.5)$ & $4(9.1)$ \\
\hline Other & $6(2.1)$ & $10(6.6)$ & $1(3.2)$ & $2(4.5)$ \\
\hline No answer & $4(1.3)$ & $1(0.7)$ & $1(3.2)$ & $16(36.4)$ \\
\hline Total & $258(100)$ & $153(100)$ & $31(100)$ & $44(100)$ \\
\hline \multicolumn{5}{|c|}{ Time of professional work experience } \\
\hline Up to 10 years & $134(45.0)$ & 104(68.0) & $22(70.9)$ & 28(63.6) \\
\hline 11 to 20 years & $61(20.4)$ & $38(24.8)$ & $7(22.6)$ & $3(6.8)$ \\
\hline More than 20 years & $103(34.6)$ & $11(7.2)$ & $2(6.5)$ & $13(29.6)$ \\
\hline Total & $258(100)$ & 153(100) & $31(100)$ & $44(100)$ \\
\hline \multicolumn{5}{|c|}{ Professional experience with alcoholics } \\
\hline Yes & $156(52.4)$ & $80(52.3)$ & $19(61.3)$ & $44(100.0)$ \\
\hline No & $142(47.6)$ & $73(47.7)$ & $12(38.7)$ & - \\
\hline Total & $258(100)$ & 153(100) & $31(100)$ & $44(100)$ \\
\hline \multicolumn{5}{|l|}{ Graduate school } \\
\hline Yes & 198(76.8) & 107(69.9) & $20(64.5)$ & $30(68.2)$ \\
\hline No & $60(23.2)$ & $46(30.1)$ & $11(35.5)$ & $14(31.8)$ \\
\hline Total & $258(100)$ & $153(100)$ & $31(100)$ & $44(100)$ \\
\hline \multicolumn{5}{|c|}{ Training to work with alcoholics } \\
\hline Yes & $119(46.0)$ & $69(45.0)$ & $10(32.3)$ & $9(20.5)$ \\
\hline No & $139(54.0)$ & $84(55.0)$ & $21(67.7)$ & $35(79.5)$ \\
\hline Total & $258(100)$ & 153(100) & $31(100)$ & $44(100)$ \\
\hline \multicolumn{5}{|c|}{ Type of training to work with alcoholics } \\
\hline Classroom & 108(41.7) & 103(67.3) & $10(33.3)$ & $19(44.4)$ \\
\hline Specific course & $126(48.8)$ & $20(13.2)$ & $14(44.4)$ & $15(33.4)$ \\
\hline Seminar & $24(9.5)$ & $30(19.5)$ & $7(22.3)$ & $10(22.2)$ \\
\hline Total & $258(100)$ & $153(100)$ & $31(100)$ & $44(100)$ \\
\hline
\end{tabular}

This study was approved by the Ethics Committee of the Nursing School of the University of São Paulo (Universidade de São Paulo - USP), process no. 709/2008, and an informed consent form was signed by each study participant. 


\section{Results}

\subsection{Socio-demographic variables}

Table 1 shows that the sample was composed mostly of women $(83.7 \%)$, with a mean age of 34.8 years $(S D=$ 9.59), who were married (43.7\%) and had less than 5 years of professional experience $(31.7 \%)$ and work experience with alcoholics $(55.5 \%)$. Regarding work experience with chemically dependent individuals, $40.7 \%$ reported having received no specific training in nursing school.

\subsection{Reliability analysis}

The reliability index (Cronbach's $\alpha$ ) of the study sample was $\alpha=0.70$.

\subsection{Nurses' attitudes}

Table 2 reveals that, in general, the 526 nurses that participated in the study, shows negative attitudes towards alcohol, alcoholism and alcoholics, since them obtained belowaverage scores on the scale as whole (mean score $=275$ ). Regarding the nurses' attitudes towards alcohol, alcoholism and alcoholics according their workplace (general hospitals - group 1, primary health care - group 2, mental health facilities - group 3 and specialized facilities - group 4), Table 2 shows that the nurses working at specialized facilities ob- tained highest scores - better attitudes, in the EAFAAA as a whole, and in its subscales 1(working and relating with alcoholics), 3(alcoholism), 5(alcoholic beverages).

Table 2 shows an analysis of the mean scores observed (obtained) in the subscales of the instrument for each group of nurses and the mean score expected in each subscale. It reveals that nurses working at specialized facilities presents higher mean scores on subscale 1 (mean score=126). In subscale 2, with the exception of nurses working in primary health care (group 2) who shows positive attitudes (mean score $=61$ ), Table 2 reveals that group 1 (nurses working at general hospitals), group 3 (nurses working at mental health facilities) and group 4 (nurses working at specialized facilities) presents a mean score lower than expected for this subscale $($ mean score expected $=60)$.

Table 2 also shows an analysis of the nurses' attitudes assessed in subscale 3 of the EAFAAA, and it reveals neutral attitudes. The analysis of subscale 4, which measures the repercussions derived from alcohol use/abuse, showed a predominance of positive attitudes, since the nurses from different settings had above average scores in the subscale 4 . Finally, Table 2 also reveals that nurses working at specialized facilities (group 4) presents neutral attitudes towards alcohol (mean score $=36$ ), while nurses from the other three groups shows negative attitudes (see Table 2).

Table 2: Observed and expected means and SD of the responses obtained in the subscales of the EAFAAA according to workplace. São Paulo, 2013

\begin{tabular}{lllllll}
\hline Workplace & $\begin{array}{l}\text { Observed } \\
\text { /expected mean } \\
\text { (SD) }\end{array}$ & $\begin{array}{l}\text { Observed } \\
\text { /expected } \\
\text { Subscale 1 }\end{array}$ & $\begin{array}{l}\text { Observed } \\
\text { Subscale 2 } \\
\text { /expected } \\
\text { mean (SD) } \\
\text { Subscale 3 }\end{array}$ & $\begin{array}{l}\text { Observed } \\
\text { /expected mean } \\
\text { (SD) } \\
\text { Subscale4 }\end{array}$ & $\begin{array}{l}\text { Observed } \\
\text { /expected mean } \\
\text { (SD) } \\
\text { Subscale 5 }\end{array}$ & $\begin{array}{l}\text { Observed } \\
\text { /expected mean } \\
\text { (SD) } \\
\text { Total }\end{array}$ \\
\hline $\begin{array}{l}\text { General hospitals } \\
\text { (Group 1) }\end{array}$ & $114 / 126(14.48)$ & $59 / 60(6.02)$ & $38 / 39(4.59)$ & $27 / 21(4.45)$ & $34 / 36(4.29)$ & $273 / 288(20.67)$ \\
$\begin{array}{l}\text { Primary health care } \\
\text { (Group 2) }\end{array}$ & $116 / 126(11.05)$ & $61 / 60(4.98)$ & $39 / 39(3.55)$ & $29 / 21(3.75)$ & $33 / 36(3.48)$ & $276 / 288(15.71)$ \\
$\begin{array}{l}\text { Mental health } \\
\text { facilities (Group 3) }\end{array}$ & $112 / 126(14.86)$ & $59 / 60(5.43)$ & $38 / 39(5.25)$ & $29 / 21(5.47)$ & $32 / 36(4.61)$ & $271 / 288(21.89)$ \\
$\begin{array}{l}\text { Specialized } \\
\text { facilities (Group 4) }\end{array}$ & $126 / 126(18.12)$ & $58 / 60(5.98)$ & $40 / 39(4.39)$ & $26 / 21(4.42)$ & $36 / 36(6.40)$ & $284 / 288(21.63)$ \\
All groups & $116 / 126(14.27)$ & $58 / 60(5.73)$ & $39 / 39(4.34)$ & $28 / 21(5.59)$ & $34 / 36(4.38)$ & $275 / 288(19.72)$ \\
\hline
\end{tabular}

Table 3 reveals results from the Kruskal-Wallis test, which was used in order to compare the nurses' attitudes towards alcohol, alcoholism and alcoholics according to workplace. There is a statistical significance $(p<.05)$ in the attitudes of the participants according to health care setting in all subscales of the EAFAAA except for subscale 3 (alcoholism), suggesting that the nurses' attitudes towards alcohol and alcohol-related problems differ depending on their health care setting.

Table 4 shows the results of the multiple comparison tests, that were used to identify the significant differences in the means obtained in the full instrument and in each of its subscales among the groups of nurses. The results were represented by the values of "critical difference" and "observed difference".

In subscale 1 (working and relating with alcoholics), Table 4 reveals a significant difference between the attitudes of nurses working at specialized facilities and nurses working at the other health care settings ("critical difference" value lower than "observed difference" value). Table 4 also re- 
veals a significant difference between the attitudes of nurses eral hospitals towards the etiology of alcoholism. working in primary health care and nurses working at gen-

Table 3: Kruskal-Wallis test of the responses obtained in the subscales of the EAFAAA according to workplace. São Paulo, 2013

\begin{tabular}{|c|c|c|c|c|c|c|}
\hline & $\begin{array}{l}\text { Subscale } 1 \\
\text { ( } p \text {-value) }\end{array}$ & $\begin{array}{l}\text { Subscale } 2 \\
\text { ( } p \text {-value) }\end{array}$ & $\begin{array}{l}\text { Subscale } 3 \\
\text { ( } p \text {-value) }\end{array}$ & $\begin{array}{l}\text { Subscale } 4 \\
\text { ( } p \text {-value) }\end{array}$ & $\begin{array}{l}\text { Subscale } 5 \\
\text { ( } p \text {-value) }\end{array}$ & Total \\
\hline Workplace & $.000^{*}$ & $.017 *$ & .719 & $.002 *$ & $.007 *$ & $.004 *$ \\
\hline
\end{tabular}

$(*)$ statistically significant at $p<.05$.

In subscale 4, which measures nurses' attitudes towards the impacts associated with alcohol use/abuse, Table 4 shows a significant difference between the attitudes of nurses working at primary health care facilities and nurses working at general hospitals, and demonstrates significant difference between nurses working at specialized facilities compared to nurses working in primary health care and mental health facilities ("critical difference" value lower than "observed difference" value). In subscale 5 (nurses' attitudes towards alcoholic beverages), Table 4 also reveals a significant difference between nurses working at specialized facilities when compared to the attitudes of nurses working at mental health facilities.

Regarding the mean values obtained for the full EAFAAA instrument, the Table 4 demonstrates that the attitudes of nurses working at specialized facilities towards alcohol, alcoholism and alcoholics were significantly less negative than those of nurses working at mental health facilities and general hospitals. Thus, our results revealed differences in nurses' attitudes depending on their health care setting.

Table 4: Multiple comparisons of the responses obtained in the subscales of the EAFAAA according to workplace. São Paulo, 2013

\begin{tabular}{llll}
\hline & Workplace & $\begin{array}{l}\text { Observed } \\
\text { difference }\end{array}$ & $\begin{array}{l}\text { Critical } \\
\text { difference }\end{array}$ \\
\hline \multirow{2}{*}{ Subscale 1 } & Group 1 X Group 4 & 94,03 & 63,23 \\
& Group 2 X Group 4 & 67,99 & 66,97 \\
Subscale 2 & Group 1 X Group 4 & 120,49 & 91,80 \\
& Group 1 X Group 2 & 40,74 & 38,94 \\
Subscale 4 & Group 2 X Group 4 & 76,47 & 66,97 \\
& Group 3 X Group 4 & 97,59 & 91,80 \\
Subscale 5 & Group 3 X Group 4 & 99,08 & 91,80 \\
\hline
\end{tabular}

\section{Discussion}

The objective of this study was to compare the attitudes of nurses working in different health care settings towards alcohol, alcoholism and alcoholics. The analysis of their attitudes assessed with the full EAFAAA instrument and each of its five subscales indicated that the nurses' attitudes differed according to health care setting. In partic- ular, nurses working at specialized facilities achieved the highest overall score as well as the highest score in the subscales that measure attitudes toward working with and relating with alcoholics (subscale 1), alcoholism (subscale 3) and alcoholic beverages (subscale 5), which was expected since as indicated by Luis and Lunetta, ${ }^{[17]}$ and Willaing and Ladelund, ${ }^{[16]}$ nurses that works in specialized settings tend to show more positive attitudes towards alcoholics and exhibit less moralistic attitudes. Regarding subscale 1, which assesses working and relating with alcoholics, the highest mean score was obtained by nurses working at facilities specialized in alcohol and other drug treatment. Indeed, nurses working directly with this population or in places with specific treatments available for alcoholics have been shown to display more humanistic behavior, without stereotypes and moral judgments. ${ }^{[16,17]}$ In general, this behavior is associated with the knowledge and practice acquired during daily contact with alcoholics in the health care facilities, which provides these nurses with a more humanistic model of work based on a broader understanding of alcoholism and the absence of moral judgment. Moreover, this contact helps to strengthen the skills taught theoretically during training that, when not associated with practice, have little influence on the attitudes of these professionals. ${ }^{[16]}$

Nurses working at mental health facilities obtained the lowest mean score in subscale 1, suggesting negative attitudes towards working and relating with alcoholics. This finding is worrisome because studies have shown that alcoholics have a high risk of comorbidity with other psychiatric disorders. ${ }^{[18]}$ Thus, these negative attitudes towards alcoholics may result in the failure to detect or address alcohol use in patients ${ }^{[19]}$ which can ultimately compromise comprehensive care and lead professionals to feel unmotivated when treating these patients. ${ }^{[8,10]}$

Nurses working in primary health care obtained the highest mean score for subscale 2 (etiology of alcoholism), indicating the presence of positive attitudes toward this subject. This finding may be associated with the organization of primary health care facilities, which attempt to introduce new practices that are in agreement with constant changes in the theories of disease causes. ${ }^{[20]}$ Specifically, these theories have changed from a mono-causal concept of disease to a concept that takes into account not only the biological 
dimension but also the relationship between lifestyle, environment and the health care system. ${ }^{[20]}$ Accordingly, this new disease etiology approach, within the biopsychosocial paradigm, may have positively affected the attitudes of these nurses toward the etiology of alcoholism.

According to subscale 2, nurses working at specialized facilities displayed negative attitudes towards the etiology of alcoholism. This finding may be explained by a failure during nursing training in aspects related to the abuse of alcohol and other drugs. Even after obtaining experience and acknowledging that the alcoholic is not an immoral individual who will be difficult to treat, as indicated in the results of subscale 1 (alcoholic), these professionals still tend to agree with moral explanations for the etiology of alcoholism, including a low educational level, lack of self-control or shyness. This finding emphasizes the importance of including theoretical lectures and practical activities related to alcohol and drug abuse in the curricula of undergraduate nursing programs, considering that the hours devoted to this subject in these curricula remain insufficient and that approaching this subject has been shown to improve attitudes and the ability to detect and treat alcoholics. ${ }^{[22]}$

The analysis of nurses' attitudes toward alcohol in subscale 5 demonstrated that except for nurses working at specialized facilities, those who participated in the study had a tendency to display negative attitudes. This finding may be associated with concepts and experiences in providing care to patients with physical complications caused by alcohol abuse, considering that approximately $41 \%$ of nurses working in specialized facilities spend $80 \%-100 \%$ of their time in contact with patients with problems associated with the abuse of alcohol and other drugs. ${ }^{[23]}$ Consequently, these professionals may obtain non-permissive or negative attitudes toward alcohol use, given the immediate perception of the effects of alcohol abuse on the patients and their families.

The experiences acquired when working with patients with complications caused by alcohol abuse may also be associated with the fact that nurses working at specialized facilities showed less positive attitudes than nurses working at primary health care and mental health facilities in subscale 4 (repercussions resulting from alcohol use/abuse). While professionals working at primary health care and mental health facilities perform specific interventions for these users, involving limited aspects of the individual's life, nurses working at specialized facilities are closely engaged with these patients and closely monitor not only their physical impairments but also the social problems caused by alcohol abuse. This fact may influence the attitudes of these nurses, considering that these consequences cause intense suffering to alcoholic patients and may also affect the professionals who monitor them.

Our finding that the EAFAAA identified differences in the attitudes of nurses from different health care settings, par- ticularly showing that nurses working at specialized facilities display more positive attitudes, suggests the discriminant validity of this instrument. A low reliability index value for the EAFAAA, as measured by Cronbach's $\alpha$ ( $\alpha$ $=0.70$ ), was obtained for this sample. Although low, this $\alpha$ value is considered acceptable for this type of study. ${ }^{[24]}$ However, the length of the instrument may have influenced the reliability index, as very long questionnaires such as the EAFAAA, which contains 90 items, may cause fatigue to the professionals who fill them out and consequently impulsive responses that reduce the reliability of the instrument. ${ }^{[25]}$ Therefore, future studies should aim to reduce the length of this questionnaire.

\subsection{Limitations}

Some limitations should be considered in the interpretation of the results of this study. In particular, because this study was conducted with nurses from specific health care facilities in the city of São Paulo, the data cannot be generalized. Furthermore, although the statistical tests did not show differences, the samples of nurses working at mental health facilities and specialized facilities were small because these facilities represent a small proportion of the health care network. Regarding the questionnaire used, the value of Cronbach's $\alpha$ was a limitation because although considered acceptable, it requires careful interpretation of the data. In addition, despite great efforts to recruit participants for the study, the sample size was limited because the nurses either did not have time to fill out or did not return the questionnaires.

However, despite these limitations, our study comparing the attitudes of nurses working at different health care settings towards alcohol, alcoholism and alcoholics may be considered innovative among the existing studies in the nursing field addressing alcohol and drugs. In addition to there being few recent studies comparing nurses' attitudes, the sample used in the present study was significant and conferred power to the data. Moreover, the results indicated that there were differences in the attitudes of these professionals according to their health care setting, which provides a basis for the training of nurses from other health care facilities to treat users of alcohol/other drugs and indicates the importance of contact with patients during training, as this aspect seems to be critical for generating more positive attitudes.

\subsection{Recommendation}

Successful strategies may include the establishment of training courses in related health care facilities, new specialized courses in alcohol and drugs (which remain scarce), the inclusion of alcohol and other drug courses in nursing undergraduate program curricula and clinical practice in specialized facilities for chemically dependent individuals. Additional studies should be performed to map and compare nurses' attitudes towards alcohol, alcoholism and alcoholics 
in several health care settings.

\section{Conclusion}

This study revealed differences in the attitudes of nurses working at different health care settings towards alcohol, alcoholism, and alcoholics. Despite the negative attitudes displayed by nurses, as assessed with the full EAFAAA instrument, significant differences were observed in the attitudes of these professionals according to their health care setting, where nurses working at specialized facilities obtained the best scores in the EAFAAA. This trend toward negative attitudes among nurses working at different health care settings suggests that education and training strategies to address both alcoholism and alcohol-related problems need to be rethought because negative attitudes impair treatment.

\section{Conflicts of Interest Disclosure}

The authors report no conflicts of interest. The authors are responsible for the content and writing of the paper.

\section{References}

[1] World Health Organization. Global Status Report on Alcohol. Geneva: World Health Organization; 2014; 376

[2] Carlini EA, Galduróz JCF, Noto AR, Nappo SA. II Levantamento domiciliar sobre uso de drogas psicotrópicas no Brasil. São Paulo (SP): Centro Brasileiro de Informações Sobre Drogas Psicotrópicas (CEBRID) - Departamento de Psicobiologia da Universidade Federal de São Paulo; 2005; 468.

[3] Santora PB, Hutton HE. Longitudinal trends in hospital admissions with co-occurring alcohol/drug diagnoses, 1994-2002. J Subst Abuse Treat. 2008; 35(1): 1-12. PMID:17935930 http://dx.doi .org/10.1016/j.jsat.2007.08.002

[4] Cherpitel CJ, Ye Y, Bond J, Rehm J, Cremonte M, Neves O, et al. The effect of alcohol consumption on emergency department service use among injury patients: a cross-national emergency room study. J. Stud. Alcohol. 2006; 67(6): 890-7. PMID:17061006

[5] Vargas D, Oliveira MAF, Araújo EC. Prevalência de dependência alcoólica em serviços de atenção primária à saúde de Bebedouro. Cad. Saúde Pública. 2009; 25(8): 1711-20. PMID:19649412 http: //dx.doi.org/10.1590/S0102-311X2009000800007

[6] Crothers CE, Dorrian J, Determinants of nurses' attitudes toward care of patients with alcohol problems. ISRN Nurs. 2011; 2011: 111.

[7] Nehlin C, Fredriksson A, Grönbladh L, Jansson L. Three hours of training improve psychiatric staff's selfperceived knowledge and attitudes toward problem-drinking patients. Drug Alcohol Rev. 2012; 31(4): 544-9. PMID:22050211 http://dx.doi.org/10.1111/j .1465-3362.2011.00373.x

[8] Warren OU, Sena V, Choo E, Machan J. Emergency physicians' and nurses' attitudes towards alcohol-intoxicated patients. J Emerg Med. 2012; 43(6): 1167-74. PMID:22525698 http://dx.doi.org/1 $0.1016 / j \cdot j$ jemermed .2012 .02 .018

[9] Spricigo JS, Alencastre MB. The nurse from health unit and the drug user: one analysis in Biguaçu/SC. Rev. latinoam. enferm. 2004; 12(spe): 427-32.

[10] Kelleher S, Cotter P. A descriptive study on emergency department doctors' and nurses' knowledge and attitudes concerning substance use and substance users. Int Emerg Nurs. 2009; 17(1): 3 14. PMID:19135010 http://dx.doi.org/10.1016/j.ienj . 20 08.08 .003

[11] Bartek JK, Lindeman M, Newton M, Fitzgerald AP, Hawks JH. Nurse-identified problems in the management of alcoholic patients. J Stud Alcohol. 1988; 49(1): 63-70.

[12] Rassool GH. Nursing and substance misuse: responding to the challenge. J. adv. nurs. 1993; 18(9):1401-07. PMID:8258598 http: //dx.doi.org/10.1046/j.1365-2648.1993.18091401.x
[13] Vargas D. Nursing students attitudes towards alcohol, alcoholism and alcoholics: a study of a brazilian sample. J. Nurs. Educ. 2012; 2(1): 01-08.

[14] Skinner N, Roche AM, Freeman T, McKinnon A. Health professionals attitudes towards AOD-related work: moving the traditional focus from education and training to organizational culture. Drugs: educ, prev policy. 2009; 16(3): 232-49. http://dx.doi.org/10. 1080/09687630902876338

[15] Willaing I, Ladelund S. Nurse counseling of patients with an overconsumption of alcohol. J. nurs. scholarsh. 2005; 37(1): 3035. PMID:15813584 http://dx.doi.org/10.1111/j.1547-5 $069.2005 .00014 . x$

[16] Luis MAV, Lunetta ACF. Alcohol and drugs: preliminary survey of brazilian nursing research. Rev. latinoam. enferm. 2005; 3(esp): 1219-30.

[17] Willaing I, Ladelund S. Nurse counseling of patients with an overconsumption of alcohol. J. Nurs. Scholarsh. 2005; 37(1): 305. PMID:15813584 http://dx.doi.org/10.1111/j.1547-5 069.2005.00014.x

[18] Sánchez-Peña JF, Alvarez-Cotoli P, Rodríguez-Solano JJ. Psychiatric disorders associated with alcoholism: 2 year follow-up of treatment. Actas Esp Psiquiatr. 2012; 40(3): 129-35.

[19] Happell B, Carta B, Pinikahana J. Nurses' knowledge, attitudes and beliefs regarding substance abuse: questionnaire survey. Nurs Health Sci. 2002; 4(4): 193-200. http://dx.doi.org/10.1046 /j.1442-2018.2002.00126.x

[20] Tanaka OY, Ribeiro EL. Ações de saúde mental na atenção básica: caminho para ampliação da integralidade da atenção. Ciênc. saúde coletiva. 2009; 14(2): 477-86.

[21] Hueso Montoro H, Siles González J, Amezcua M, Bonill de las Nieves C, Pastor Montero S, Celdrán Mañas M. Understanding the suffering of a patient with an illness:signs, context and strategies. Rev. Latinoam. enferm. 2012; 20(3): 619-28.

[22] Rassool GH, Rawaf S. Educational intervention of undergraduate nursing students' confidence skills with alcohol and drug misusers. Nurse educ. today. 2008; 28(3): 284-92. PMID:17643558 http: //dx.doi.org/10.1016/j.nedt.2007.06.001

[23] Roche AM, Pidd K. Alcohol and other drug workforce development issues and imperatives: setting the scene. Adelaide (SA): National Centre for Education and Training on Addiction (AU). Australia; $2010 ; 112$.

[24] Field A. Discovering Statistics Using SPSS.3th ed. London: Sage Publications Ltd; 2010

[25] Cronbach LJ. My current thoughts on coefficient alpha and sucessors procedures. Educ. Psychol. Meas. 2004; 64(3): 391-418. http: //dx.doi.org/10.1177/0013164404266386 